\title{
Potential Safety Benefit of the Blind Spot Detection System for Large Trucks on the Vulnerable Road Users in Taiwan
}

\author{
Ming-Hang Wang ${ }^{1}$ and Chien-Hung Wei ${ }^{2}$ \\ ${ }^{1}$ Assistant Professor, Department of Transportation Technology and Management, Kainan University, Taoyuan City, Taiwan \\ ${ }^{2}$ Professor, Department of Transportation and Communication Management Science, National Cheng Kung University, Taiwan City, Taiwan
}

\begin{abstract}
Considering motorcyclists, pedestrians and bicyclists as vulnerable road users (VRUs), more than 75 percent of the victims of fatal crashes involving large trucks in Taiwan are VRUs. Most crashes occurred at or were due to the blind spots of large trucks because of the size and traveling locations of the VRUs. This study applies typology and statistical methods to estimate the potential safety benefit of blind spot detection (BSD) systems for large trucks on VRUs. The pre-crash scenarios associated with the blind spots of large trucks were derived by counting the maneuvers of large trucks and VRUs, prior to crashes, the truck drivers' improper behaviors (cause of crashes), and the crash types. The number of crashes and fatalities were counted for the pre-crash scenario relevant to the BSD systems. A value of 0.8 of human machine interface factor (HMIF) based on a previous study was applied to estimate the potential safety benefits of the BSD system. The results show that the implementation of BSD systems on all large trucks could help avoid about 24, 10, and 11 percent of large truck-involved crashes with pedestrians, bicycles, and motorcycles, respectively. The BSD systems could also save 5 pedestrians, 3 bicyclists, and 15 motorcyclists per year from crashes involving large trucks.
\end{abstract}

\section{Introduction}

Advanced vehicle safety systems (AVSs) are designed to help avoid vehicle crashes or reduce the severity of crashes by providing warning signals to drivers or automatic actions for vehicles when vehicles are facing potential collision circumstances. As innovative wireless and image detection technologies are developed, various types of AVSs are embedded into new cars. However, the popularity of AVSs is still limited due to a lack of laws and awareness of AVS technologies. To enhance traffic safety, several countries have been emphasizing the standardization of AVSs on new vehicles. Since 2007, the United States [1], and Europe [2] and Australia have been making the electronic stability control (ESC) mandatory on new vehicles.

Several researches have been conducted to estimate the potential safety benefit of AVSs using various methodologies. Blower et al.[3] reviewed the current state of knowledge regarding the effectiveness of several advanced collision-avoidance technologies (ACATs) and presented an assessment of the effect of each technology on traffic safety for light-duty vehicles. Overall, the systems reviewed were estimated to be substantially effective in reducing their target crash types.

In Taiwan, due to the high number of motorcycles, more blind spot detection functions that can detect motorcycles traveling beside trucks along the street, pedestrians crossing in front of the large trucks are needed. Considering motorcyclists, pedestrians and bicyclists as vulnerable road users (VRUs), more than 75 percent of the victims of fatal crashes involving large trucks are vulnerable road users according to the national police-reported crash database from 2009 to 2014. Among crashes involving large trucks with pedestrians and bicyclists, about 40 percent of the fatal crashes occurred when the large trucks were starting off and making right or left turns. It is believed that most crashes occurred at or are due to the blind spots of the large trucks. Thus, the implementation of blind spot detection (BSD) system in large trucks is an essential and urgent task to avoid large trucks crashing into VRUs.

In order to increase the public's awareness of the function of AVSs on road safety, particularly for large trucks on VRUs, this study applies typology and statistical methods to estimate the potential safety benefit of BSD systems for large trucks on VURs based on the national police-reported crash database in Taiwan. The pre-crash scenarios associated with the blind spot of the large truck were derived by combining the truck drivers' improper behaviors (cause of crashes), the truck's movement prior to the crash, and the collision part of the large trucks corresponding to the crash types. Next, the statistical method is used to calculate the potential safety benefits in terms of the frequency and fatalities of the crashes relevant to the BSD systems. Finally, the results and the limitations of this study, as well as further studies 
for extending the method to other AVS technologies, are discussed and recommended.

\section{Blind spot detection systems}

The blind spot is the area not covered by the driver's line of sight and mirrors, alongside and off-set to the rear of the moving car on both sides. The BSD technology uses radar, cameras or ultrasonic technologies to monitor the blind spot area of the vehicle. If a moving object is detected within the specified zone, a warning signal is issued. Warning signals vary from one version of the system to another and include visual, audio or haptic signals. Essentially, most BSD systems were designed to alert the driver that another vehicle may be present and to use caution if planning a lane change [4]. Some BSD systems were also developed particularly for detecting vulnerable road users in a truck's blind spot zone [5][6][7] using camera detection technology.

The potential benefits of the BSD systems were estimated by several researches. In Europe, the BSD could save approximately 975 lives each year and avoid 2,100 injuries, through the crash causation analysis [8]. In the U.S., it can avoid 457,000 injuries and 428 fatalities per year [9], and prevent 39,000 large truck-involved crashes including 79 fatal crashes per year [10] based on the pre-crashes scenario analysis. Other research used depth clinical reviews for each case [11] and found that the BSD can avoid 5.9 percent of crashes involving large trucks. In Germany, it could avoid about 24.7 percent of crashes [12].

However, the benefits of the BSD systems were assessed for passenger cars only. Most BSD systems may not always detect all vehicles located in a car's blind spot. In particular, narrow and often fast moving vehicles such as motorcycles are easy to miss [13]. The potential of the technology to assist Heavy Goods Vehicles (HGVs) drivers to detect VRUs in their blind spot should also be investigated. Users, such as cyclists, are particularly at risk when they find themselves in the blind spot of an HGV. The development and deployment of reliable technologies enabling the recognition of pedestrians and cyclists while they are in the blind spot of HGVs should be a priority.

In Taiwan, due to specific traveling characteristics of a high number of motorcycles, additional blind spot detection functions that can detect the motorcycles traveling beside the trucks along the streets are needed. A blind spot detection system was developed by the Automotive Research \& Testing Center (ARTC), a benchmark automotive R\&D institute in Taiwan [14]. The Taiwanese BSD system was developed by using image-based object recognition, image-feature analysis, object/space measurement, and signal integration. The BSD system is adopted to detect the status of approaching objects (including all types of vehicles, bicycles and pedestrians) in both left and right side blind areas by active image recognition processes of machine vision. This BSD system has been verified that the accuracy rate is 91 percent and the frame rate is more than 20 frames per sec (fps), in day and night and all weather conditions [14]. The blind spot areas which the Taiwanese BSD can detect include the front side, rear side, front lateral sides and rear lateral sides. Based on the detected areas, the systems provide the approaching object detection and door opening warning function.

The Taiwanese BSD system was extended to large trucks by mounting cameras on several parts of a semitrailer to detect any object in front of the heavy vehicle. As the object with defined characteristics in the blind area is detected, the system issues the pre-warning (lighting) or warning (beep and lighting) messages to the driver.

Although the BSD technologies are developed, the potential safety benefit on traffic crashes and fatality reduction have not been estimated. This study will estimate the potential safety benefit if all large trucks are equipped with truck BSD systems.

\section{Crash database}

The crash data for this study is provided by the National Police Administration (NPA) of Taiwan. Data on crashes involving large trucks and VRUs, such as pedestrians, bicycles, and motorcycles for the years 2009-2014, were extracted from the nationwide traffic crash database. Large trucks are defined as cargo vehicles with a gross vehicle weight $(\mathrm{GVW})$ over $3,500 \mathrm{~kg}$. The NPA crash database only includes crashes in which at least one road user is killed or injured. The crash is considered fatal if at least one person died within 30 days of the collision.

The NPA crash dataset contains the information on the characteristics of the crash, the road environment, people (e.g., drivers, bicyclists, and pedestrians) and units. The characteristics of the crash include the month, date, time of day, and crash location. The road environment data contain the information on road types, control devices, and geometry deployment (e.g. the direction or lane divisions, and sight distance condition). The characteristics of truck drivers and VRUs including the personal information (e.g., age, gender), impaired condition, and the injuries sustained (e.g., fatal, injury, or no injury) are also provided. The unit data recorded the movement manners of the vehicles prior to the crashes, damage, first collision part of the vehicle, and crash type, as well as the major/minor causes of the crashes. This data can then be used to identify the possible scenarios prior to the crashes.

\section{Methods}

\subsection{Pre-crash Scenario technologies}

Due to low penetration rates of vehicles with the AVSs, most studies relied on simulations or limited field operational tests to evaluate the effectiveness of AVSs [4]. In the U.S., a number of crash typologies have been developed and widely been used to provide a common foundation to develop and estimate potential safety benefits of effective crash countermeasure systems [15][16][17][18]. Yanagisawa et al., [19] analyzed the national crash databases from National Highway Traffic 
Safety Administration (NHTSA) to identify the pre-crash scenarios for the Pedestrian Crash Avoidance/Mitigation (PCAM) systems. Safety benefits, in terms of pedestrian injuries avoided and pedestrian injuries mitigated, are expressed in terms of reductions in annual harm measures. Toma et al. [20] describes pre-crash scenarios involving at least one large truck, which might be avoided with crash-imminent warning systems based on short range vehicle-to-vehicle (V2V) communications.

In Europe, Papps et al., [21] estimated the potential proportion of injury accidents that could be avoided and/or the severity of the accidents that could be reduced, for future and existing safety functions, by means of the Traffic Accident Caution in Europe (TRACE) projects. They assessed the effectiveness for 19 advanced safety devices including the BSD system. They counted the main maneuver of vehicles and crash types, which is relevant to the BSD. The results indicate that the BSD could lead to about a 2 percent reduction in injury accidents and related casualties. However, they only considered the effective-ness between passenger cars.

In this study, the possible crash scenario due to or at the blind spots of large trucks are categorized by using the "if the drivers were warned, would the crash be avoided?" method. Thus, five major attributes available in the existing national police administration (NPA) crash database were investigated. They are: (1) maneuver of the large truck prior to the crashes; (2) maneuver of the VRUs prior to the crashes; (3) crash contributions due to the large trucks; (4) crash types; and (5) first collision spot on the trucks. These attributes were used to generate the pre-crash scenarios which could possibly be avoided by the implementation of the BSD systems.

\subsubsection{Maneuvers of large trucks prior to the crashes}

Truck's Maneuvers is counted to identify whether the objects (VRUs) appeared within the blind spots, and determine whether the crash could be avoided or not. It also can be used to identify if the crashes resulted from the off tracking of the trucks. In general, crashes occur due to or at the blind spots when the trucks are:

- Starting off (TSO) from the road side or stop line;

- Turning Right (TTR);

- Turning Left (TTL)/U-turn (TUT);

- Changing Lane (TCL);

- Parking or backing operation (TPB); or

- Parked (TPK).

A parked truck could result in crashes when the driver opens the door carelessly (ODC) without checking for approaching bicycles/ motorcycles.

\subsubsection{Maneuvers of the VRUs prior to the crashes}

The VRU's maneuver was checked to further confirm the direction and relative position between trucks and VRUs, and also to determine if the VRUs appear within the blind area. Because pedestrians are in slow moving situations comparing to the trucks, any maneuvers could possibly be detected and avoid the crashes in time. For bicycles and motorcycles, changing lane or turning movements may be detected by the BSD system, but may not prevent the crashes in time. Thus, the maneuvers of the bicycles or motorcycles relevant to the BSD system are:

- Going Straight (VGS): same direction with truck;

- Parked (including temporary parked) (VPD): which is in still condition.

- Turning Right (VTR); or

- Turning Left" (VTL): same direction with truck.

\subsubsection{Cause of crash by trucks}

Truck's contribution factor was inspected to identify whether the drivers were driving carefully or already noticed the appearance of the VRUs or not. Theoretically, under careless or improper driving scenarios, the crashes could be avoided if the drivers were warned of the appearance of the VRUs. Particularly when the objects appear within the blind spots, these crashes could be avoided. The major causes due to the truck drivers are:

- Failing to look properly (FLP);

- Turning Improperly (TIP);

- Backing Carelessly (BCL);

- Failing to Keep the Safe Side Gap (FKSG); or

- Changing Lane Improperly (CLIP).

\subsubsection{Crash types and first collision spot on trucks}

Crash types and collision spots on trucks should be checked simultaneously to identify the relative position between trucks and VRUs. For pedestrian-related crashes, the first collision spot on the truck body should be taken into account to check which spot of the truck hit the pedestrian. For instance, pedestrians hit by the front head of trucks may be due to the blind spot in front of the trucks.

For crashes with bicycles or motorcycles, the crash types occurring at the blind spots of trucks could be side effect (SE), same direction side swipes (SSW). When trucks are starting off from the stop line or road sides, the trucks may collide into stopped bicycles or motorcycles due to the blind spot in front of the trucks. The collision spots are recorded in the NPA crash database as the first collision spot (FCS), including:

- Front head (FH);

- Right Front(RF)/Right side (RS)/Right Rear(RR);

- Rear end (RE);

- Left Front(LF)/Left side (LS)/Left Rear (LR)

Table 1. Pre-crash Scenario for large truck crashes with pedestrian relevant to the BSD system.

\begin{tabular}{|c|c|c|c|c|c|}
\hline $\begin{array}{c}\text { Pre-crash } \\
\text { Scenario }\end{array}$ & $\begin{array}{c}\text { Maneuvers } \\
\text { of large } \\
\text { trucks }\end{array}$ & $\begin{array}{c}\text { Maneuvers } \\
\text { of VRUs }\end{array}$ & Cause by LT & $\begin{array}{l}\text { Crash } \\
\text { Type }\end{array}$ & $\begin{array}{l}\text { First collision } \\
\text { spot on truck }\end{array}$ \\
\hline P1 & TSO & \multirow{7}{*}{ Any } & FLP/FKSG & \multirow{7}{*}{$\begin{array}{l}\text { Crash with } \\
\text { Pedestrian }\end{array}$} & Any expect RE \\
\hline \multirow{2}{*}{ P2 } & \multirow{2}{*}{ TPBO } & & FLP/BCL & & \multirow{2}{*}{ Any spots } \\
\hline & & & /FKSG & & \\
\hline \multirow{2}{*}{ P3 } & \multirow{2}{*}{$T T R$} & & FLP/TIP & & \multirow{2}{*}{$\mathrm{FH} / \mathrm{RF} / \mathrm{RS} / \mathrm{RR}$} \\
\hline & & & /FKSG & & \\
\hline P4 & $T T L$ & & FLP/TIP/FKSG & & LF/LS/LR \\
\hline P5 & TCL & & FKSG/CLIP & & $\mathrm{RF} / \mathrm{RS} / \mathrm{RR}$ \\
\hline
\end{tabular}




\subsection{Pre-crash Scenario}

Based on the principles described above for determining the scenarios which could be avoided by BSD systems, the pre-crash scenarios were proposed in Table 1 and Table 2 for crashes with pedestrians, bicycles and motorcycles, respectively. The maneuvers and characteristics of bicycles and motorcycles are similar expect for the traveling speeds. The crash scenario for bicycles and motorcycles should be similar.

Table 2. Pre-crash Scenario for large truck crashes with bicycles/motorcycles relevant to the BSD systems.

\begin{tabular}{|c|c|c|c|c|c|}
\hline $\begin{array}{c}\text { Pre-crash } \\
\text { Scenario }\end{array}$ & $\begin{array}{c}\text { Maneuvers } \\
\text { of large } \\
\text { trucks }\end{array}$ & $\begin{array}{c}\text { Maneuvers } \\
\text { of VRUs }\end{array}$ & $\begin{array}{c}\text { Cause by } \\
\text { truck }\end{array}$ & $\begin{array}{c}\text { Crash } \\
\text { type }\end{array}$ & $\begin{array}{c}\text { First } \\
\text { collision } \\
\text { spot on } \\
\text { truck }\end{array}$ \\
\hline B1/MB1 & TSO & $\begin{array}{l}\text { VPD/VSP } \\
\text { /VSO/VGS }\end{array}$ & FLP/FKSG & any & $\begin{array}{l}\text { Any but } \\
\text { rear end }\end{array}$ \\
\hline \multirow{2}{*}{ B2/MB2 } & \multirow{2}{*}{ TPBO } & \multirow{2}{*}{$\begin{array}{l}\text { VPD/VSP } \\
\text { /VSO/VGS }\end{array}$} & $\mathrm{FLP} / \mathrm{BCL}$ & \multirow{2}{*}{ any } & \multirow{2}{*}{ Any spots } \\
\hline & & & /FKSG & & \\
\hline \multirow{2}{*}{ B3/MB3 } & \multirow{2}{*}{$T T R$} & \multirow{2}{*}{$\begin{array}{c}\text { VGS/VPD } \\
\text { /VTR }\end{array}$} & FLP/TIP & \multirow{2}{*}{ SE/SSW } & \multirow{2}{*}{$\begin{array}{l}\mathrm{FH} / \mathrm{RF} \\
/ \mathrm{RS} / \mathrm{RR}\end{array}$} \\
\hline & & & /FKSG & & \\
\hline B4/MB4 & TTL/TUT & $\begin{array}{c}\mathrm{VPD} / \mathrm{VGS} \\
\text { /VTL }\end{array}$ & $\begin{array}{c}\mathrm{FLP} / \mathrm{TIP} / \mathrm{FK} \\
\mathrm{SG}\end{array}$ & ssW & LS/LF/FR \\
\hline B5/MB5 & $\mathrm{TCL}$ & VGS & \begin{tabular}{|l|} 
FKSG/CLIP \\
\end{tabular} & SE/SSW & $\mathrm{FR} / \mathrm{RS} / \mathrm{RR}$ \\
\hline B6/MB6 & TPD & VGS & ODC & ODC & ${ }^{*} \mathrm{LS}$ \\
\hline
\end{tabular}

$*$ : NPA database does not specify the door as collision spot.

\subsection{Potential safety benefits estimation}

The descriptive statistical method is used to calculate the potential safety benefits in terms of the frequency and fatalities of the crashes for each scenario relevant to the truck's BSD system. Theoretically, the crashes could be avoided by the drivers' reaction when the BSD sends the warning signal (or sound) to the driver. However, in reality, some drivers may not react in time or may not act the proper way to prevent the crashes. The human machine interface factor (HMIF) will affect the appropriate ratio of drivers' reactions. The HMIF is a value between 0 and 1 . The theoretical BSD should be multiplied by the HMIF in order to determine the achievable safety potential of BSD systems.

A value of $\mathrm{HMIF}=0$ indicates the system is not achievable in reality because of a poor interface design. A value of $\mathrm{HMIF}=1$ means that the theoretical $\mathrm{BSD}$ can be achieved in reality. For the BSD systems, the HMIF can be assumed to be 0.8 in accordance to the research conducted in Germany [22] referred in [12]. However, an additional filed test of the BSD system is necessary to estimate a precise value of HMIF.

\section{Results analysis}

\subsection{Facts of crashes involving large trucks and VRUs}

From 2009 to 2014 (6 years), a total of 34,945 large trucks were involved in 33,580 crashes, leading to 2,141 deaths (6.4 percent) and 38,261 injuries. Among those large truck involving crashes, more than 70 percent were
VRU related (64.8 percent of motorcycles, 3.6 percent bicycles, and 2.7 percent pedestrians). In terms of deaths, 1,339 are motorcyclists (62.5 percent), 147 are cyclists (6.9 percent), and 144 are pedestrians (6.7 percent). The fatality rate of a motorcyclist crashing with a large truck is 5.3 percent. For pedestrians and bicyclists, the fatality rate is 15.2 percent and 11.9 percent, respectively, when they collide with a large truck.

To identify the major causes of the crashes, crashes with other non-VRUs were excluded for the analysis. Thus, crashes with only one large truck crashing with VRUs were used for the analysis. A total of 21,820 crashes $(19,879$ crashes with motorcycles, 742 crashes with pedestrians, and 1,199 crashes with bicycles) were analyzed. Among these crashes, 123 pedestrians, 145 bicyclists, and 1,120 motorcyclists were killed.

\subsection{Crashes and fatalities relevant to BSD systems}

Table 3 summarizes the numbers of crashes and fatalities relevant to the BSD systems based on the pre-crash scenarios.

Table 3. Numbers of crashes and fatalities relevant to the BSD systems.

\begin{tabular}{|c|c|c|c|c|c|c|c|c|c|c|}
\hline \multicolumn{3}{|c|}{ vs. pedestrians } & \multicolumn{3}{|c|}{ vs. Bicycles } & \multicolumn{3}{|c|}{ vs. Motorcycles } & \multicolumn{2}{|c|}{ vs. Al VRUs } \\
\hline $\begin{array}{l}\text { Pre-crash } \\
\text { scenario }\end{array}$ & $\begin{array}{c}\text { No. of } \\
\text { Fatalities }\end{array}$ & $\begin{array}{c}\text { No. of } \\
\text { Crashes }\end{array}$ & $\begin{array}{l}\text { Pre-crash } \\
\text { scenario }\end{array}$ & $\begin{array}{l}\text { No. of } \\
\text { Fatalities }\end{array}$ & $\begin{array}{c}\text { No. of } \\
\text { Crashes }\end{array}$ & $\begin{array}{l}\text { Pre-crash } \\
\text { scenario }\end{array}$ & $\begin{array}{l}\text { No. of } \\
\text { Fatalities }\end{array}$ & $\begin{array}{l}\text { No. of } \\
\text { Crashes }\end{array}$ & $\begin{array}{c}\text { No. of } \\
\text { Fatalities }\end{array}$ & $\begin{array}{c}\text { No. of } \\
\text { Crashes }\end{array}$ \\
\hline P1 & 29 & 86 & B1 & 5 & 20 & MB1 & 13 & 491 & 47 & 597 \\
\hline P2 & 4 & 58 & B2 & 1 & 18 & MB2 & 32 & 783 & 37 & 859 \\
\hline P3 & 2 & 30 & B3 & 15 & 70 & MB3 & 38 & 1004 & 55 & 1104 \\
\hline P4 & 3 & 45 & B4 & 0 & 1 & MB4 & 1 & 59 & 4 & 105 \\
\hline \multirow[t]{2}{*}{ P5 } & 0 & 5 & B5 & 1 & 18 & MB5 & 26 & 303 & 27 & 326 \\
\hline & & & B6 & 0 & 15 & MB6 & 0 & 116 & 0 & 131 \\
\hline Sum & 38 & 224 & & 22 & 142 & & 110 & 2756 & 170 & 3122 \\
\hline $\begin{array}{l}\% \text { of } \\
\text { Total }\end{array}$ & $30.9 \%$ & $30.2 \%$ & & $15.2 \%$ & $11.8 \%$ & & $9.8 \%$ & $13.9 \%$ & $12.2 \%$ & $14.3 \%$ \\
\hline Total & 123 & 742 & & 145 & 1199 & & 1120 & 19879 & 1388 & 21820 \\
\hline
\end{tabular}

Theoretically, if all large trucks were equipped with BSD systems, they could prevent 14.3 percent of large truck-involved crashes with VRUs, and save 170 lives of VRUs in 6 years (28.3 per year).

For the large truck-involved crashes with pedestrians, about 27 percent of crashes, and 24 percent of pedestrian fatalities were relevant to the blind spots of the trucks. Among these crashes during the "starting off" stage (86 crashes), half of all fatal crashes, pedestrians were hit by the front head of the trucks.

For the crashes with bicycles, the BSD system can possibly prevent about 12 percent of crashes, and 15 percent of bicyclist fatalities. Most crashes and fatalities could be avoided, by about 5 percent and 10 percent, respectively, by the BSD systems when trucks were turning right at the intersections (Scenario B3).

For the crashes with motorcycles, the BSD system could possibly decrease the crashes by 14 percent and fatalities by 10 percent. Most crashes (about 5 percent) could be avoided by BSD systems during the "turning right" stage of the trucks (Scenario MB3). That is because most motorcycles are traveling on the right side of the trucks. Potential traffic conflicts occur between 
trucks and motorcycles at trucks' blind spots when trucks turn right. The BSD systems are more effective for preventing the crashes when the trucks are in slow movements, such as 'starting off", "parking or backing operation". During these processes, the BSD could possibly decrease more than 6 percent of crashes and 4 percent of fatalities of motorcyclists.

\subsection{Potential safety benefits of BSD systems}

If the 0.8 HMIF was applied, the BSD system could avoid about 24 percent of large truck-involved crashes with pedestrians, 10 percent of crashes with bicycles, and 11 percent of crashes with motorcycles. The BSD system could also reduce 19 percent of fatalities for pedestrians, 12 percent for bicyclists, and 8 percent for motorcyclists among the large truck-involved crashes. These are about, on average, saving 5 pedestrians, 3 bicyclist, and 15 motorcyclists per year.

\section{Conclusions and recommendations}

The benefits of the AVSs based on the data from other countries are not applicable during the process of the standardization of AVSs. Prior AVS systems are also different from other countries' systems. Due to the high number of motorcycles in Taiwan, additional blind spot detection functions that can detect motorcycles traveling beside the trucks are needed.

To increase the public's awareness of the functions of advanced vehicle safety systems (AVSs) on road safety, particularly for large trucks on VRUs, this study applies typology and statistical methods to estimate the potential safety benefit of BSD systems for large trucks on the VRUs. The results show that theoretically the BSD system could prevent 14.3 percent of large truck-involved crashes with VRUs, and save 170 lives of VRUs in 6 years (28 per year). When the HMIF (0.8) was considered, the BSD system could avoid about 24 percent of crashes with pedestrians, 10 percent of crashes with bicycles, and 11 percent of crashes with motorcycles. The BSD system could also save about 5 pedestrians, 3 bicyclists, and 15 motorcyclists per year from the crashes involving large trucks. However, since the HMIF may vary from country to country, further field tests are needed to obtain the suitable HMIF for the Taiwanese BSD. The combinations of other AVSs, such as automatic emergency braking systems, will increase the safety benefit of the BSD systems.

\section{Acknowledgement}

This research is sponsored by Ministry of Science and Technology of Taiwan (No.MOST-104-221-E-424-001).

\section{References}

1. US Department Of Transportation, 49 CFR Parts 571 and 585- Federal Motor Vehicle Safety Standards, Docket No. NHTSA 2005-20586
2. The European Parliament and Council, REGULATION (EC) No 661/2009, (13 July 2009)

3. D. Blower, Final Report, The University of Michigan Transportation Research Institute, (2014)

4. G. Forkenbrock, R. L. Hoover, E. Gerdus, T. R. Van Buskirk, and M. Heitz, Report No. DOT HS 812 045, Washington, DC: NHTSA, (2014)

5. K. Van Beeck, T. Goedem'e, and T. Tuytelaars, Proc. MVA, Nara, Japan, (2011)

6. K. Van Beeck, T. Tuytelaars, and T. Goedem'e, Proc. ICINCO, (2012)

7. K. Van Beeck, and T. Goedemé, Proc. the 3rd International Conference on Pattern Recognition Applications and Methods, 412-420, Angers, France, (March 2014)

8. eImpact, Assessing the Impacts of Intelligent Vehicle Safety Systems, Socio-economic impact assessment of stand-alone and co-operative Intelligent Vehicle Safety Systems (IVSS) in Europe, (2008)

9. Insurance Institute for Highway Safety (IIHS), Researchers Estimate Potential Benefits of Crash Avoidance Features, Status Report 43, 3 (April 17, 2008) | SPECIAL ISSUE: CRASH AVOIDANCE FEATURES |

10. Insurance Institute for Highway Safety (IIHS), Large Trucks to Benefit from Technology Designed to Help Prevent Crashes, Status Report 45, 5 (May 20, 2010)

11. K. J. Kingsley, NHTSA, Paper No. 09-0460, (2009)

12. M. Kuehn, T. Hummel, and J. Bende, No. 09-0317. 21st International Technical Conference on the Enhanced Safety of Vehicles, Stuttgart, Germany

13. Fédération Internationale de l'Automobile (FIA), policy position on the general safety regulation, (2014)

14. C. T. Chen and Y. S. Chen, ITSC '09. 12th International IEEE Conference on Intelligent Transportation Systems, (2009). St. Louis, MO

15. NAO Engineering, Safety \& Restraints Center, Crash Avoidance Department, "44 Crashes". General Motors Corporation, Version 3.0, (January 1997)

16. Crash Avoidance Metrics Partnership, "Enhanced Digital Mapping Project - Final Report". U.S. Department of Transportation, National Highway Traffic Safety Administration, (November 2004)

17. W. G. Najm, B. Sen, J. D. Smith, and B. N. Campbell, DOT-VNTSC-NLTSA-02-04, DOT HS 809 573, (February 2003)

18. W. G. Najm, J. D. Smith, and M. Yanagisawa, Report No. DOT HS 810 767. Washington, DC: NHTSA, (2007)

19. M. Yanagisawa, E. Swanson, and W. G. Najm, Report No. DOT HS 811 998. Washington, DC: NHTSA, (2014)

20. S. Toma, D. Swanson, and W. G. Naim, Report No. DOT HS 812 023. Washington, DC: NHTSA, (2014)

21. Page, $Y$ et al. D 4.2.1 - A posteriori evaluation of safety functions effectiveness -Methodologies, TRACE Report, (2007) 
22. B. Färber, F. Freyberger, and B. Färber, Nutzenpotenzial von Fahrerassistenzsystemen. Literaturstudie, Expertenbefragung, Bewertung, On behalf of the German Insurers Accident Research. Unpublished , (2008) 